\title{
Putting calories on menus in Ireland: what consumers want
}

\author{
F. E. Douglas ${ }^{1}$, A. E. Bennett ${ }^{1}$, L. Courtney ${ }^{1}$, E. Keaveney ${ }^{1}$, E. Crowley ${ }^{1}$, M. A. T. Flynn ${ }^{1}$ \\ ${ }^{1}$ Public Health Nutrition, Food Safety Authority of Ireland, Dublin 1, Republic of Ireland
}

Calorie menu labelling in restaurant chains may help combat obesity even where only modest changes occur in consumer behaviour ${ }^{(1)}$. Consumers who report using calorie information $(15 \%)$ tend to make lower calorie food choices ${ }^{(2)}$. The purpose of this study was to determine, through national consultation, consumers' views on calorie menu labelling in Ireland.

Information on the obesity epidemic in Ireland, calorie menu labelling in other countries and what consumers could expect should this be implemented in Ireland was provided on the Food Safety Authority of Ireland website. Submissions from the public via a short on-line Consumer Survey, accessible for four weeks, were invited by press release. Quantitative and qualitative information collected included submitters' background, their views on calorie menu labelling - whether this should be implemented and in which food outlets - and whether this should be mandatory for large food businesses (defined by number of outlets). Submitters were asked if they would trust the calorie information. Data was analysed using $\chi^{2}$ to test for differences according to submitters' background.

\begin{tabular}{|c|c|c|c|c|c|c|c|c|c|c|}
\hline & \multirow{2}{*}{\multicolumn{2}{|c|}{$\frac{\text { Total Group }}{n 3130}$}} & \multirow{2}{*}{\multicolumn{2}{|c|}{$\begin{array}{c}\text { Consumer } \\
n 2666 \\
\end{array}$}} & \multirow{2}{*}{\multicolumn{2}{|c|}{$\begin{array}{c}\text { Healthcare Professional } \\
n 322\end{array}$}} & \multirow{2}{*}{\multicolumn{2}{|c|}{$\begin{array}{c}\text { Food Business } \\
n 73 \\
\end{array}$}} & \multirow{2}{*}{\multicolumn{2}{|c|}{$\begin{array}{c}\text { Other } \\
n 69\end{array}$}} \\
\hline & & & & & & & & & & \\
\hline & $\%$ & (n) & $\%$ & (n) & $\%$ & $(n)$ & $\%$ & (n) & $\%$ & $(n)$ \\
\hline In all food outlets & 83 & $(2585)$ & 85 & $(2269)$ & 75 & $(241)$ & 37 & (27) & 70 & $(48)$ \\
\hline In some food outlets & 13 & $(396)$ & 11 & (288) & 20 & $(64)$ & 36 & (26) & 26 & (18) \\
\hline In no food outlets & 4 & $(131)$ & $4 *$ & (94) & $5^{*}$ & (16) & $25^{*}$ & (18) & $4 *$ & (3) \\
\hline Don't know & 1 & (18) & 1 & (15) & 1 & (1) & 3 & (2) & 0 & $(0)$ \\
\hline
\end{tabular}

$* p<0.001$.

As shown in the table above, $95 \%$ want calorie menu labelling in all or some food outlets. Those wanting calorie labelling in some outlets want this in fast food outlets (95\%), followed by coffee shops \& delis $(63 \%)$, cinemas $(58 \%)$, vending machines $(57 \%)$, pubs $(26 \%)$ and restaurants $(18 \%)$. The main reasons given for wanting $v s$. not wanting calorie menu labelling was 'empowerment to make informed food choice decisions' vs. 'calorie labelling is unnecessary and ineffective' (46\% vs. $3 \%$ of the total group respectively). Significantly more submissions from food businesses, compared to submissions from any other background, did not want calorie menu labelling in any food outlet $(p<0.001)$. Significantly more submissions from consumers, healthcare professionals and others, compared with those from food businesses, wanted mandatory calorie menu labelling $(92 \%, 88 \%, 84 \%$ vs. $58 \%$ respectively; $p<0.001)$ and would trust calorie information $(62 \%, 51 \%, 59 \%$ vs. $36 \%$ respectively; $p<0.001)$.

This study shows there is overwhelming support from consumers for calorie menu labelling in Ireland. The number of submissions to this consultation was unprecedented. Previously, the best response to a national consultation, which concerned the addition of folic acid to bread and was supported by commercial advertising, received 513 submissions.

1. Simon P, Jarosz CJ, Kuo T, et al. (2008) Am J Public Health 99, 1680-1686.

2. Dumanovsky T, Huang CY, Nonas CA, et al. (2011) Br Med J 343, 4464-4475.

3. Food Safety Authority of Ireland (2006) available at: www.fsai.ie/WorkArea/DownloadAsset.aspx?id=770 